\title{
The Harmonious Development of the Packing Material and Environmental Protection
}

\author{
Chengrui Duan ${ }^{1}$, Xiaodan $\mathrm{Li}^{2}$ and Zhenhua $\mathrm{Xu}^{3}$ \\ ${ }^{1}$ Shenyang Aerospace University, Shenyang \\ ${ }^{2}$ Shenyang University, Shenyang \\ ${ }^{3}$ Shenyang Aerospace University, Shenyang
}

\section{Keywords: Environmental protection; Packing material; Design}

\begin{abstract}
Environmental protection is the development theme in the world today. With the development of the economy, the environment attracts people's attention more and more and has become a common problem faced by human in the 21 st century. The impact of packing materials on the environment is an important topic of the current environmental protection. In this paper, we elaborate the influence of packing materials on environmental protection.
\end{abstract}

\section{Introduction}

Environmentally-friendly packing is also called sustainable packing. It is reusable and recyclable commodity packing which can save packing material resources and reduce packaging waste. It includes packing materials which are harmless to the environment and human health, plastic packages which possess the biodegradability, recyclable glass containers, etc. After entering the 21 st century, countries around the world increase the intensity of the environmental protection. European Union (hereinafter referred to as EU)also enacts some green laws and regulations which are "The Restriction of the Use of Certain Hazardous Substances in Electrical and Electronic Equipment", "Waste Electrical and Electronic Equipment", "Registration, Evaluation, Authorization and Restriction of Chemicals", etc. After these regulations are enacted, EU also enacts the directive of EUP which requires all energy products that use electricity, solid fuels, liquid fuels and gaseous fuels to take the energy conservation as the center. And the ecological design of the whole process of product life cycle is made in order to improve the access threshold for products to enter the EU again.

Environmental protection design of products involves the environmental protection design of the packing. The core of the environmental protection design is to use environmental protection packing materials. Especially, in the context of calling the security of foods and drugs by countries around the world, environmental protection packing materials of foods and drugs should be developed urgently. Therefore, the development of environmental protection packing materials has become a great hotspot which is researched, developed and produced by packaging industry, especially by packing materials industry in the current world. This paper will discuss the development trend of the environmental protection package.

\section{Environmental Factors to Improve the Packing Design}

Environmental protection needs comprehensive implementation of various measures which include law, policy, management, assessment, technology, etc. According to the theory of the value in use of commodity packages, the environmental protection property of commodity packaging involves social rules and regulations, waste disposal, resource utilization and other problems. As the packing designer, the vital link "packing design" of the packing engineering should be used to improve the green efficiency of the package. The packing design should save packing materials and reduce the waste of resources maximally in order to save resources and maintain the ecological equilibrium.

Whatever the environmental protection concept of commodity packages researches the value of commodity packages statically or researches the value in use of commodity packages dynamically, 
the aim of it is to seek the right selection and development of commodity packages, and the final target is to seek the rationalization of commodity packages. Packing design should pay attention to the following factors:(1) Packing materials and packing containers should be safe and harmless and there should be no hazardous substances such as poliklorobifenil in packing materials. The appropriate standard should be enacted in order to make the intensity of the wrappage protect commodities appropriately. Modelling of packaging containers shouldn't damage human and environment.(2)The problem of excess caused by large packing volume should be avoided. For example, for some tea packages and mooncake packages, there is a delicate wooden box with a layer of foam in a big carton, on the foam there is a layer of yellow silk which wraps two tins and in tins there are real commodities. This kind of packing not only wastes packing materials and has a surplus packing intensity but also has a high sales price. It misleads consumers and is also a fraudulent conduct[1].(3)The packing should be convenient for the governance of the waste and reduce the amount of its waste. When commodities are produced and sold, we should pay attention to the volume of packages in order to dispose the packing waste conveniently. Inspecting from the angle of the whole society, this is because that the packing is the appendage of commodities and it has the materiality. Packing brings plenty of rubbish to the human society and the pollution to the environment. Also packing will cause the resource consumption and bring some noxious substances to consumers. Various technologies (especially the packing design) should be adopted to eliminate these negative effects to turn bane into a boon.

The environmentally-friendly packing will focus on the ecological equilibrium relationship between human and nature and the design strategy should be made to reduce the destruction of the environment as much as possible. In the full life cycle of the commodity packing, the functional requirement of the packing should be satisfied, the ecological environment shouldn't be polluted, the human health shouldn't be harmed, and meanwhile, the packing can be recycled and reused and also can meet the requirement of the sustainable development. The requirement of the environmentally-friendly packing should achieve 3R1D principle which is reducing, reusing, recycling and degradation. And it takes a full account of the impact of the whole life cycle of the packing on resources, energy and ecological environment, focus on reducing the environmental loads of packing materials and achieve the equilibrium and unity of the functionality of the packing and environmental adaptability. The environmentally-friendly packing design puts the concept of environmental protection throughout the each link of packing design. In that way, resources will be saved and the packing will also meet requirements of environmental protection and the sustainable development of economy and society.

\section{Packing Materials}

According to relevant materials, the current annual output of plastic packing in our country is more than 2 million tons and the disposable plastic packing which is difficult to recycle accounts for $30 \%$ of it. And the other statistics show that the wastes of our country are more than 16 million tons every year, of which the wastes of plastic packing products are up to 1 million per year. Plastic packing products mainly include plastic packing lunch boxes, plastic plates, foam materials, beverage bottles, plastic packing of kinds of candies and foods and various plastic packing bags. According to the experts, the pollution of white trash on environment will last a long time and is difficult to eliminate.

The packing designer as the leader of commodity packing should have a strong sense of environmental protection, fully consider the box structure, the usage of materials and the printing craft of the packing and the aspect of trash disposal. The packing should be designed reasonably and the material of the packing should be reduced as much as possible and also the packing should be beautiful and practicable. The environmentally-friendly packing design should become the direction of future development. Meanwhile, the packing design should advocate developing environmentally-friendly packing materials with the ecological performance, increase the recycling of materials and save the global resources. The glass bottles of beer, beverage, soy, vinegar and so on are recyclable materials. Renewable materials mean that after the polyester packaging is recycled, 
it can be reused through physical method and chemical method. For example, paper materials are widely used in the packaging industry. The paper is mainly made of natural vegetable fiber which will be quickly decomposed in nature and recycled and the pollution of paper materials is also very low.

Plastic Packing Materials. The proportion of plastic packing materials in packing waste is the largest and it is about $40 \%$. Also the pollution of plastic packing materials on environment among various packing materials is the most serious[2][3]. For example, the EPS foam plastic lunch boxes and their cushion packaging bring lots of white trash to cities. There are 100 thousand tons of EPS foam lunch boxes waste in Guangzhou alone every year. In addition, the foaming agent CNC (chloro-fluoro alkane)of EPS will damage the atmospheric ozonosphere and the plastic packing materials will be also difficult to degrade. When plastic packing materials are burned, the harmful gas will be produced. Therefore, human should devote themselves to research and develop new-style plastic packing materials to reduce and eliminate the impact on the environment. The following aspects are included: The first one is lightweight, slim and high-performance plastic. In order to reduce the total amount of plastic packing waste, each country competes to develop high-performance materials to reduce the thickness of containers and thin films. Japan has developed coriaceous and ultrathin PET thin film. The thin film's thickness is $0.5 \mu \mathrm{m}$ and it is used for the packing of precision electronic components. The liquid crystal polymer thin film LCP which is successfully developed by America is composed of special dense fibrous polymer long bond. The intensity and toughness of LCP are much higher than those of other films, such as PET. When LCP's thickness is $2 \mu \mathrm{m}$, the gas barrier property of it is equivalent to the gas barrier property of EVOH whose thickness is $25 \mu \mathrm{m}$. LLDPE which is developed by Mobil Chemical company replaces the HDPE. The intensity of LLDPE improves but the thickness of it decreases by $30 \%$. Finland also develops a kind of OPA/PE laminated film whose thickness decreases by $1 / 3$ but the other properties of it are not affected. The second one is fluoride-free foamed plastic[4]. Because of the large consumption of foam plastic lunch boxes and cushion packaging materials, people are researching and developing a new-type foamed plastic foaming agent to replace CNC. Now the ideal dichloromethane foaming PS, PP and PET can be used for the packing of foods and electronic products. The highly efficient fluorine free instapack polyurethane foaming agent which is developed by America can be used to foam with little material and the material can be used repeatedly and it is also easy to burn. In addition, the CANNON company in Italy also uses $\mathrm{CO} 2$ foam polyurethane which is more secure and not pollute the environment. The third one is reusable and renewable plastic. If the plastic packing material and container can be used repeatedly, the consumption of raw material and the pollution of the environment can be reduced. Because of the good comprehensive mechanical properties and heat canned ability of PET, every country of Europe and America begins to use PET bottles which are packing for milk and beverage repeatedly. For example, the Wellman company in Holland and Johnson company in America makes the 100\% recycling for the PET bottle. Plastic recycling is a good method to solve the problem of plastic waste pollution and also can provide some raw materials or energy for industrial production. After the plastic is recycled, it should be smashed through physical method and then be used for the production of plastic containers or films. For example, after the PET bottles are smashed and then made again, there is no change in physical, chemical and comprehensive mechanical properties. In addition, the plastic can be decomposed into oligomers or monomer by chemical method, which can be used to produce plastic again. Also the plastic can be cracked into small molecule fuel to produce fuel oil. Therefore, packing should adopt the material which is easy to recycle and reuse, such as PET and PP.

Appropriate Packaging Should is advocated in Design. Currently, the excessive packaging has become an environmental pollution source which cannot be neglected. People must pay more attention to solve this problem. Developed countries have limited the excessive packaging from the perspective of legislation and many countries stipulate that the packaging cannot be greater than $1 / 10$ of the volume of the packaging. German which firstly promoted packaging materials recycling developed a "Circular Economy Law". Denmark took the lead in the implementation of "green tax" 
system. Many countries require manufacturers, importers and retailers to take responsibility for recycling and reproducing packaging materials. In South Korea, excessive packaging items are illegal. In order to implement the goods packaging ratio and the limitation of the number of layers, the South Korean government will check the packaging of goods, give award to compact packaging and impose a fine of the excessive packaging of goods.

Environmental Protection and Green Concept Should be highlighted in the Content of the Packing Design. At the present, the function of the packaging is no longer limited to meet the logistics and aspect of protecting products. Packaging is also an important way for enterprises to deliver product information and business philosophy. If designers can add the "green" and "environmental protection" information into the content of the packing design, not only the enterprise's "green" business philosophy can be reflected, but also the trust and identity of consumers can be enhanced. Therefore, in the delivery of the information of the packing design, the information of environmental protection should be emphasized and publicized. The atmosphere of green packaging should be exuded in design, product name, color and text to form the mainstream of the design to spread. In the design process, the harmony of design and production, the tacit understanding of production and consumption and the harmony of life and ecology should be felt.

\section{Packing Material Recycling}

Recycling packing material waste can not only save resources but also can save energy to make it have a good energy loss ratio. For example, recycling waste paper to produce the pulp can save over $60 \%$ energy and water resources more than the pulp which is made by wood; recycling waste plastics to produce new packing containers can save $85 \% \sim 96 \%$ energy more than the using of new resins; recycling aluminum pots to produce new containers can save $95 \%$ energy more than the exploitation of bauxite and aluminum metallurgy to make new containers; recycling waste metal buckets and waste glasses to produce new containers can save $50 \% \sim 75 \%$ energy more than the exploitation of ironstone and quartz sand to produce new containers[5]. Therefore, the recycling of packaging waste resources and the reduction of packaging materials constitute the foundation of the sustainable development of packaging. The European Commission believes that iron and steel packaging can maximize the number of repeated use of natural resources, thus carbon dioxide emissions can be reduced. Therefore, it should be included in sustainable consumption and production action plan. The Hewlett-Packard Company which is the biggest manufacturer of reciprocating engine in America pay more attention to the efficient logistics packaging which can be used repeatedly and it believes that it is the development direction of sustainable packing and also it believes that packing industry should develop toward four aspects which are efficient products, efficient packaging, efficient transportation efficiency and efficient solutions[6]. The packaging container which can be reused for many times is most used in the beverage industry. The classic example is: Sweden and Germany use high-end cleaning and sterilization technology to make PET bottles and carbonate bottles can respectively be reused more than 20 times and 100 times[7].

\section{Suggestions on Promoting Environmentally-Friendly Packing Design}

The government department should fund relevant experts to make the research on the practicability of LCA assessment system of packing system and the construction of the database, aiming at relevant problems of promoting environmentally-friendly packing currently. Also the government should develop a uniform standard of the environment pollution which is caused by goods of each cycle level in the process of product recycling, provide relatively perfect nouns, symbols, parameters, operation steps and analysis methods which are adapted to packing commodity LCA, enhance the propaganda and encouragement measures of environmental protection packaging, research and develop the new environmentally-friendly packing material with low price, perfect the legislative work and establish and perfect the legal system of the environmental protection 
packaging design to make the promotion of the environmental protection packaging design and supervision work depend on the law.

\section{Conclusion}

Biodegradable packaging materials have become the packing materials for hot development in many countries and some products have been put into the industrial production. In this century, two problems faced by human are the environmental problem and energy problem. The development of packing materials has caused great changes in the packaging industry, but various material pollution has a strong impact on the residential environment and the ecological environment of human day by day. Meanwhile, nonreusable materials can cause a huge waste of resources. Therefore, the development of packing materials should develop and research biodegradable packing materials and give the reusability to various biodegradable materials. Only in this way, resources can be saved and the environment can be protected.

\section{References}

[1] C.Li: Analysis of Over-Packing [J], Packing Engineering, 2002, 23(5):226-227. (In Chinese)

[2] P.C.Zhang, etc: The Discussion of the Pollution and Its Treatment Process of Plastic Packing Products [J], Packing World, 1999(1): 5T6. (In Chinese)

[3] P.Huang, ect: My Opinion of Curbing White Pollution and Developing Green Package [J] ,China Packaging, 1998(2): 39. (In Chinese)

[4] Z.Huang, etc: The Progress of Green Packing Materials [J], Packing World, 1998(3):44. (In Chinese)

[5] H.M.Dan: Packing and Environment [M], Beijing, The Printing Technology Press, 2007. (In Chinese)

[6] Y.W.Tan: The Chemical Recycling Method of Waste Polyester[J], Synthetic Fiber in China, 2011(4): 1-7. (In Chinese)

[7] S.G.Zhu and X.Xia: The Craft and Technology of Molded Pulp [M], Beijing Machine Press, 2007:278-300. (In Chinese) 